\title{
The path to the 2017 Nobel Prize in Physiology or Medicine
}

\author{
K. Lalchhandama \\ Department of Zoology, Pachhunga University College, Aizawl 7960oI, India
}

\begin{abstract}
Jeffrey C. Hall, Michael Rosbash and Michael W. Young are selected to receive the 2017 Nobel Prize in Physiology or Medicine 2017 "for their discoveries of molecular mechanisms controlling the circadian rhythm". They discovered clock genes and their protein-products that control the circadian rhythm in the fruit fly, Drosophila melanogaster. Starting with their work on the major clock gene period (per) in the 1980s, they subsequently discovered novel genes such as Clock, cry, cycle, dbt, pdp1, per, tim, vri, and their mutations that affect the fruit fly daily behaviours. With the proteins these genes produce, their discoveries have established the understanding of a complex molecular network of clock genes and proteins. This comprehensive knowledge further enrich our perception of circadian rhythm in other animals, including us. Behind this knowledge is the foundation of understanding of many disease and health-related issues concerned with our genetics, hormones, and behaviour. Their discoveries are befitting of the Nobel Prize, but it is a bit of an irony that the pioneer discovers have already died and will forever be denied of their deservedly fame. The epoch-making discovery of per gene was in fact by Seymour Benzer and his student Ronald J. Konopka discovered in 1971. Konopka especially continued as one of the leading scientists, in many of the later discoveries. But life and luck for Nobel fame ran out for them.
\end{abstract}

Key words: Nobel Prize; clock genes, circadian; Drosophila.
Received 25 October 2017 Accepted 30 October 2017

*For correspondence $\bowtie$ chhandama@pucollege.edu.in

\section{Introduction}

Have you ever wondered why we become sleepy and fall asleep at night, and awake during the day? Do you know that animals do the same? Even nocturnal animals such as fireflies, cockroaches, bats, owls, tarsiers, aye-ayes, etc. have a regular sleep-wake cycles? Furthermore, are you aware that plants too know when to absorb $\mathrm{O}_{2}$ and release $\mathrm{CO}_{2}$ ? Do you believe that all of us, all organisms from the smallest bacteria to blue whale and giant sequoia, are controlled by a biological clock inside us?

Yes, all organisms from bacteria to humans respond to the day-night cycle. This is because we live on the same planet Earth, and the Sun, as our common source of light and energy, influences us all. Light is the most important environmental cue that entrains our sleep-wake behaviours. It is the sunlight that tells us when to sleep and when to remain awake. This biological principle is called photoperiodism. A day-night cycle is called circadian rhythm. The term circadian comes from Latin circa, meaning "around", and diēm, meaning "day". Thus, circadian rhythm is a 24-hour cycle covering one night and one day. Circadian rhythm changes with seasonal changes, from winter, spring, 
summer, to fall; and this cycle is called circannual rhythm (from Latin circa and annus, meaning "a year"). The branch of biology dealing such cycles is called chronobiology (from Ancient Greek xpóvos (khrónos), meaning "time"). Genes produce proteins to exert their effects, and those genes involved in circadian rhythms are called clock genes. Adaptation to the circadian rhythm is so ingrained in us that the clock works even in abnormal day or night situations.

The Nobel Assembly at Karolinska Institutet has chosen three American biologists Jeffrey $C$. Hall, Michael Rosbash and Michael W. Young to receive the 2017 Nobel Prize in Physiology or Medicine 2017 "for their discoveries of molecular mechanisms controlling the circadian rhythm" (Fig. 1). ${ }^{[1]}$ Jeffrey C. Hall (born 1945 in New York) and Michael Rosbash (born 1944 in Kansas City) are biology professors at Brandeis University at Waltham, Massachusetts; and Michael W. Young (born 1949 in Miami) is at the Rockefeller University in New York. Their breakthrough discovery was in 1984 using the fruit fly Drosophila melanogaster. Hall and Rosbash isolated and cloned the gene called period (per) and showed that the gene is responsible for circadian rhythm. ${ }^{[2][3]}$ At the same time, Young and his colleagues also discovered similar effects of per. $^{[4][5]}$ They are extraordinarily lucky for the Nobel Prize -as providence would have itpeople before them had already discovered the gene.
Sir Richard J. Roberts, the 1993 Nobel Prize in Physiology or Medicine laureate for the discovery of introns, wrote in 2015 "Ten Simple Rules to Win a Nobel Prize" in which he remarks, "If you are lucky, you will make a big discovery that may even bag you a prize or two. But only if you are extraordinarily lucky will you stand any chance of winning a Nobel Prize. They are very elusive."[6] The first-known clock gene, per gene was discovered way back in 1971 by an American physicist-geneticist Seymour Benzer and his student Ronald J. Konopka at the California Institute of Technology (Fig. 2). But they will never win the much deserved Nobel Prize, the Nobel statute prohibits nomination beyond the graveBenzer kicked the bucket in 2007, and Konopka followed suit in 2015. Nobel Foundation was too slothful for them.

\section{A Fly on the Wheel of Biology}

Small size is not to be underestimated. Biology in large part owes its development to the fruit fly Drosophila (Fig. 3), because it is an easyto-use genetic animal model-conveniently tiny to handle, easily reared in large number, and has short life cycle. Drosophila has offered us the key to understanding genetics, to be precise, mutations and their effects. It has also given us the deepest information on the light entrainment mechanism in organisms, and how this maintains circadian rhythm. This was estab-
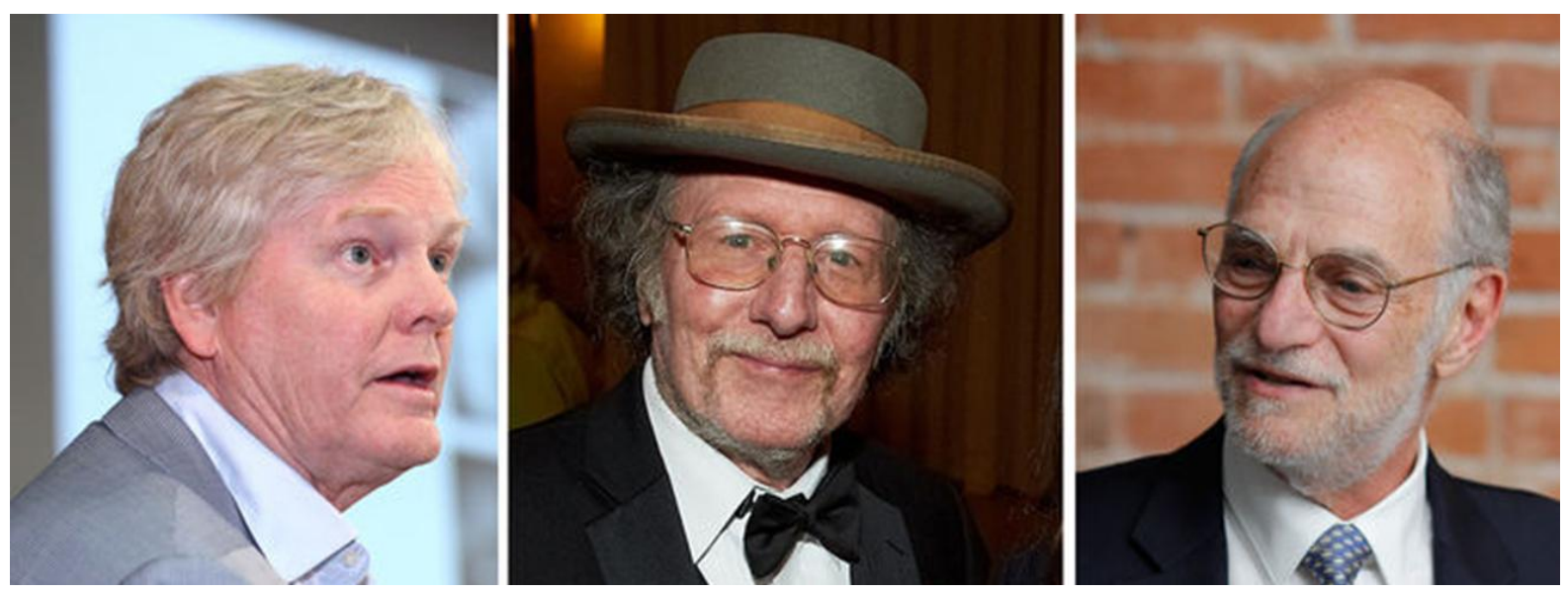

Fig. 1 | 2017 Nobel Prize in Physiology or Medicine goes to Michael Young, Jeffrey Hall, and Michael Roshbash. 


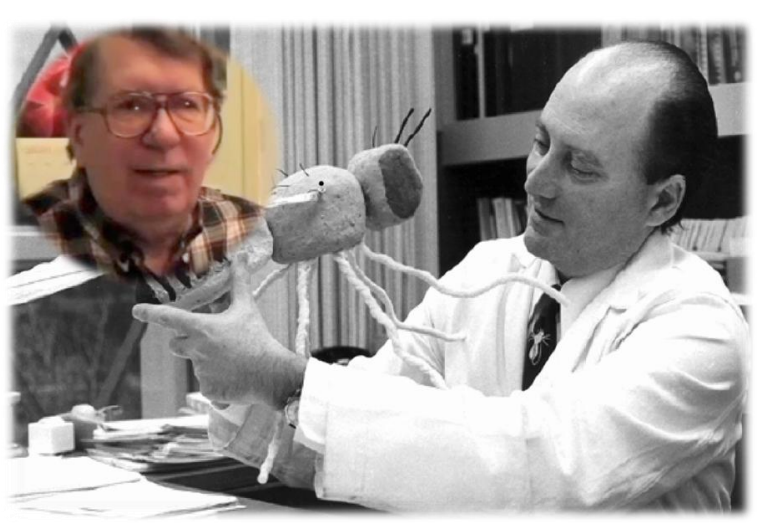

Fig. 2 | The pioneers. Seymour Benzer toying with his Drosophila melanogaster. (Inset:: Ronald J. Konopka)

lished from its unique behavioural cycles of restactivity during development and adulthood. In constant light-dark (LD) cycles, circadian activity fluctuates in a bimodal fashion in the morning and evening, and peaks at dawn and dusk. The curious thing is that these rhythms are freerunning and persist in continuous darkness, which indicates that environmental light might be the principal stimuli, but there is an internal biological clock that works even in the absence of light.

An important circadian behaviour during Drosophila development is eclosion, the process by which an adult fly emerges from the pupa at the end of larval metamorphosis. During eclosion, Drosophila exhibits regular locomotor activity (by vibration) that occurs at 8-10 hours intervals starting just before dawn. This specific activity signifies their original adaptation to their ancestral homeland in Sub-Saharan Africa, where moisture essential for haemolymph pressure will be most abundant at dawn. The Swedish naturalist Carl Fredrik Fallén was pedantically spot on to give the name Drosophila-from

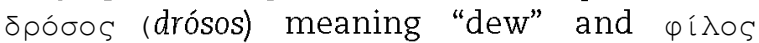
(philos) meaning "loving"; hence, "dew-lover"in 1823. The peak activity is always at the time when dawn is about to break, i.e. about 1 to 2 hours before sunrise.

The existence of this circadian clock system was independently discovered in 1935 by two German zoologists, Hans Kalmus at the Zoologi-

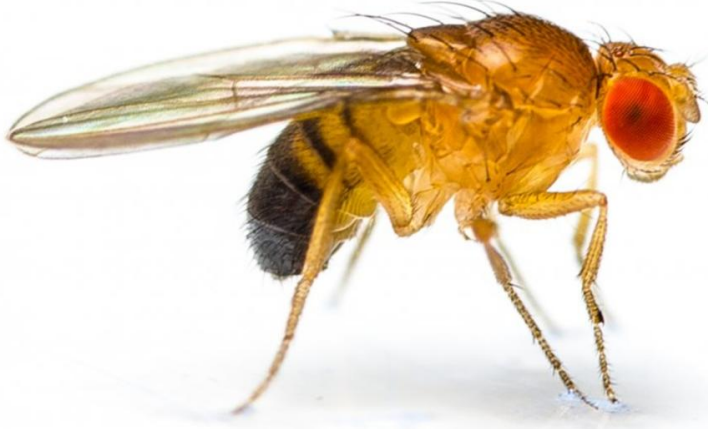

Fig. 3 | The supermodel of biology. Drosophila melanogaster.

cal Institute of the German University in Prague, [7] and Erwin Bünning at the Botanical Institute of the University of Jena ${ }^{[8]}$ They independently showed that the pupal hatching is delayed by several hours when temperature was reduced by $10^{\circ} \mathrm{C}$. Bünning also showed that the clock went haphazard (arrhythmia) when the flies are maintained in continuous dim light, but after fifteen generation rhythmicity was restored when exposed to light. Kalmus discovered in 1938 that the clock that drives eclosion resides deep inside the head of the fly ${ }^{[9]} \mathrm{He}$ was of the conclusion that the clock was driven by temperature, increased temperature shortens the cycle, and vice versa, ${ }^{[10]}$ because it was obvious that temperature is an important factor in triggering various stages of development. But he was wrong. It was later understood that such biological clocks are not directly influenced by environmental factors. Temperature, as was appreciated, has an irregular and violent fluctuation, and thus, would only create a heavily mistimed clock-a faulty biological clock never tells the right time. On the other hand, normal endogenous clocks works perfectly even under environmental adversaries or experimental manipulations. ${ }^{[11]}$ Colin S. Pittendrigh at the Princeton University reported in 1954 the significance of light-dark conditions. He observed that in the absence of light, temperature does play a role in the clock cycle. He cultured pupae of flies (in this case D. pseudoobscura) under 12:12 hour 
light/dark (LD) cycle in varying temperature, such as 16,21 and $26^{\circ} \mathrm{C}$. When he transferred the flies to total DD condition, the rhythms persisted until adults emerged, and rhythm was longer by about half an hour in flies at $16^{\circ} \mathrm{C}$ in comparison to those at $26^{\circ} \mathrm{C}$. He made a logical conclusion that temperature influences only the peak hour ; hence, exerts a very minor effect. ${ }^{[12]}$

A physicist by training, Benzer's interest was to solve biological problems as inspired by Erwin Schrödinger's book What Is Life? Spending almost two decades at Purdue University working on phage (T4 bacteriophage) genetics, he joined Caltech in 1967. He immediately turned his attention to Drosophila genetics of behaviour. That very year he reported that induced mutation renders male Drosophila unable to respond to light, that is, they become nonphototactic. ${ }^{[13]} \mathrm{He}$ established that mutation could be an important tool for studying unique biological behaviours, and made an insightful prediction, saying:

Since it is now possible to produce very high mutation rates in Drosophila, one can, instead, use an inbred strain and isolate mutants in which a behavioural change occurs by a single step, so that direct relationships between individual genes and the nervous system may be investigated.

With his student Konopka, Benzer eventually demonstrated that circadian rhythm of eclosion could be understood from gene mutation. Reporting in 1971, they discovered that due to different mutations, D. melanogaster can have faster, slower, or a complete absence of circadian rhythms. In fact, they were the first to identify a clock gene in any organism. As their new gene controls the period of circadian rhythm, they called it period (per for short). Based on the degree of mutation, there could be four different individuals: ${ }^{[14]}$

1. Normal (wild type, per), in which there is no mutation and the circadian rhythm is normal $\sim 24 \mathrm{~h}$.

2. Arrhythmic, which has no functional gene; hence called $\left(p^{\circ} r^{\circ}\right)$, and there is no rhythm at all.

3. Short-period, which has mutant gene called pers, and very short rhythm $19 \mathrm{~h}$.

4. Long-period, which has mutant gene called per ${ }^{\mathrm{L}}$, and extended rhythm $\sim 29 \mathrm{~h}$.

They further discovered that the mutation occurred on one of the $\mathrm{X}$ chromosomes at position X: 2.58-2.59. It was the discovery of the first dedicated gene that controls behaviour of any kind in any organism. But theirs was the time when the nature and function of genes were not yet fully comprehended. Other scientists remained sceptical, and discarded the notion that genes would directly control such complex behaviours, and not the less that such mutations would be responsible for circadian activities. The research was practically (almost entirely, but for the perseverance of Kanopka) put to a barren cessation for a decade.

While Benzer departed towards other genetics of behaviour, Konopka remained embroiled in the dilemma of circadian genetics. ${ }^{[15]}$ Konopka found in 1980 that mutations in the circadian gene change the location of neurosecretory cells in the fly brain. ${ }^{[16]}$ In 1981, he identified the per locus on X chromosome (position 3B1-2) responsible the three mutant per alleles, and that the per locus shorten, lengthen, or eliminate periodicity by respectively increasing, decreasing, or eliminating per activity. ${ }^{[17]}$

\section{Nobel Prize Works}

\section{In the beginning}

Another circadian behaviour in Drosophila is courtship between male and female for mating. Mating activity is driven by two mechanisms: one is a circadian pacemaker consisting of clock genes, and the other is the direct effect of light. Mating activity involves courtship song accompanied by a ritual locomotory dance in male. The main flight activity generally takes place in the morning and another peak occurs before sunset. Courtship song is produced by the male's wing vibration and consists of pulses of tone produced at intervals of approximately 34 msec in D. melanogaster (48 msec in D. simulans). In 1980, Hall and his student Charalambos P. Kyriacou discovered that courtship activity is also controlled by per gene. For instance, they showed that courtship is short in pers individual, 
long in per individual, and absent in per ${ }^{\mathrm{I}}$ individual. ${ }^{[18]}$

The pivotal discoveries were made in 1984. Hall and Rosbash's team isolated and analysed DNA sequences encompassing the per locus, and found a short stretch that is strongly modulated by a light/dark cycle. ${ }^{[2]}$ They, with Konopka, subsequently demonstrated that mutations in per cause circadian disruption such as in locomotor and courtship activities, and that when the normal per sequence is incorporated into a mutant fly, circadian rhythm is restored ${ }^{[3]}$ Around the same time Young and his team showed that females carrying only one dose of this X-linked gene have circadian rhythms with periodicities about $1 \mathrm{~h}$ longer than those carrying two doses..$^{[4]}$ They identified that the gene covers 7.1-kilobase interval on the $\mathrm{X}$ chromosome and encodes a 4.5 $-\mathrm{kb}$ poly $(\mathrm{A})+\mathrm{RNA}$. When this sequence is introduced into the genome of a per $^{\circ}$ (arrhythmic) fly by $\mathrm{P}$ element-mediated transformation, circadian rhythmicity of behaviour such as eclosion and locomotor activity is restored. ${ }^{[5]}$ In 1986 , they sequenced the entire DNA fragment, and confirmed that the locus is the active gene. Mapping of this transcription unit revealed that it encodes the 4.5-kb RNA, which codes for a protein, composed of 1,127 amino acids. ${ }^{19 !}$ The same year, Konopka, Rosbash, Hall et al. found that the 4.5-kb RNA transcript level oscillates exactly as the circadian rhythm, and implying that it, with its DNA complimentary sequences in the per gene, is the main source of rhythmicity. ${ }^{[20]}$

The effects of genes are mediated by the proteins that they produce. Rosbash and his team found in 1986 that per gene produces a protein, which is a member of proteoglycans, and the protein is absent in mutant per ${ }^{[21]}$ This indicates that loss of circadian rhythmicity is due to the absence of the protein. The protein produced by per is variously known as PER, period circadian protein, or protein clock-6. PER protein became the first of the three founder members of the PAS domain family, followed by ARNT (Aryl hydrocarbon nuclear translocator) and SIM (singleminded). These three proteins constitute a group of transcription factors known as PAS domain family, members of which are found in prokaryotes and eukaryotes, suggesting their common ancestry as clock proteins. ${ }^{[2]}$

In 1987, Hall and Rosbash's team showed that arrhythmia is a nonsense mutation in the third coding exon of a 4.5-kb RNA transcribed from this locus. The mutation is also a single nucleotide substitution, in the fourth coding exon, which results in a serine-to-asparagine substitution in PER protein. ${ }^{[23]}$ The same year, Young and his team showed that different per mutants have different substitution, and these mutations produce different amino acids in the PER protein. Slightly altered proteins produce different. In short, the protein product of per controls biological rhythms such that per ${ }^{\mathrm{L}}$ and per $^{s}$ mutants produce hypoactive and hyperactive PER proteins, respectively. In other word, flies with lowest levels of PER have slow-running biological clocks. ${ }^{[24]}$ In 1988, Hall and Rosbash's team then went on to discover that PER is the factor for a free-running circadian rhythm, and is produced maximally at night and is degraded during the day ${ }^{[25]}$ Thus, PER protein levels wax and wane over a 24-hour cycle, with peak production in the middle of the night. In 1990, they found out that the synthesis of per mRNA oscillates as that of PER proteins, which indicates that PER influences its own gene, that a feedback loop (now referred to as transcriptiontranslation feedback loop, TTFL) exists. ${ }^{[26]}$

\section{The plot thickens}

In 1994, Young and his team discovered another mutation not involving per gene but that could stop circadian rhythm. Regardless of whether the per is normal or mutant, when this gene has mutation, the fruit fly invariably becomes arrhythmic. They identified the gene on the left arm of chromosome 2 and called it timeless (tim). They further noted that tim alters circadian oscillations of per mRNA, suggesting that tim and per act concertedly, and that tim influences the activity of per. ${ }^{[27]}$ In 1995, they isolated the PER and TIM proteins. They also showed that TIM binds to PER to form a heterodimer, and this TIM-PER complex is actually responsible for con- 
trolling the duration of circadian rhythm. ${ }^{[28]}$ The tim mRNA oscillations were found to be dependent on the presence of PER and TIM proteins, indicating similar feedback control of tim by a mechanism (TTFL) previously shown to regulate per expression. The cyclic expression of tim influences the timing of PER accumulation and nuclear localisation, suggesting that tim promotes per and tim transcription by restricting per mRNA and PER protein accumulation to separate the times of day. ${ }^{[29]}$ This was a discovery that not only per, but both per and tim are essential for production of circadian rhythms in Drosophila. Then, in the same year, they sequenced the gene as well as the protein. TIM protein is composed of about 1389 amino acids, and possibly another protein of 1122 amino acids. Mutation in tim stops the circadian rhythm, as the mutant protein cannot trigger the circadian rhythm. The arrhythmic mutation, designated tim ${ }^{01}$, is a 64base pair deletion that truncates TIM to 749 amino acids. ${ }^{\left[{ }^{30]}\right.}$ In 1996, they established that the activity of tim is influenced by light, as the TIM protein is rapidly degraded upon exposure to light. ${ }^{[31]}$

\section{Big fleas have little fleas}

The story of tiny TIM does not end there. There are times when tim does not control per. In 1998, Young and his team discovered a new clock gene on chromosome 3 which they called doubletime (dbt). dbt exists in three alleles, short$\left(d b t^{S}\right)$ and long-period $\left(d b t^{L}\right)$ mutants alter both behavioural rhythmicity and molecular oscillations from previously identified clock genes, per and tim. A third allele, $d b t^{p}$ causes pupal lethality and eliminates circadian cycling of PER and TIM in larvae. In $d b t^{p}$ mutants, PER proteins constitutively accumulate, remain hypophosphorylated, and no longer depend on TIM proteins for their accumulation. DBT protein thus reduces the stability and the level of accumulation of monomeric PER proteins. This would promote a delay between per/tim transcription and PER/TIM complex function, thereby abrogating rhythmicity. ${ }^{[32]}$ DBT protein is an enzyme of casein kinase $1 \varepsilon$.

Another clock gene mutant was first noted by
Konopka, Rosbash, Hall et al. in 1987. When they induced mutation in the $\mathrm{X}$ chromosome, the mutant Drosophila displayed distorted rhythm, much like per $^{\circ}$ mutant; but with a subtle twist. The new mutants had locomotor activity rhythm of $\sim 22.5 \mathrm{~h}$, that is $\sim 1.5 \mathrm{~h}$ shorter than the normal. They exhibited weak, long-period rhythms of locomotor activity in constant darkness, instead of lack of circadian rhythm in per ${ }^{0}$ mutant. In contrast, they showed normal courtship activity. The researchers named the mutant per $^{04}$. But they noticed that the mutation was not related to the usual per mRNA. ${ }^{[33]}$ In 1990, they identified the location of the gene on the $\mathrm{X}$ chromosome, and called it, guess what? Clock (Clk). The mutant $\mathrm{Clk}$, as they uncovered, shortened the circadian cycle by 1.5 hours. ${ }^{[34]}$

A mutation on $\mathrm{X}$ chromosome with the opposite effect was discovered by Konopka's team in 1991. Reciprocal to $\mathrm{Clk}$, the mutation lengthens the period of the circadian eclosion and locomotor activity rhythms by $1.5-2.0$ hours. Since it slows down the rhythm, they named the mutant gene Andante (And). ${ }^{[35]}$ Andante is semi-dominant and also control other genes; such as lengthening the periods of other clock gene mutants, including Clk, and alleles of the per locus. In 1994, they discovered a new mutant, a reciprocal gene which acts as an ultrafast clock, called per ${ }^{\mathrm{T}}$. This gene is also semidominant and interact with the long-period Andante allele. ${ }^{[36]}$ In 2002, Roshbash's team discovered another mutation called Timekeeper (Tik). Tik is a unique dominant allele, homozygous condition of which is lethal. Like And, it also lengthens the rhythm by degrading PER protein. ${ }^{\left[{ }^{[3]}\right.}$ It was then realised that And and Tik code for the same protein casein kinase type 2 (CK2)-And codes for the $\alpha$ chains, and Tik for the $\beta$ chains. (The Drosophila CK2 was isolated in 1983 as a regulatory enzyme in development and was found to consist of two $\alpha$ chains and two $\beta$ chains. ${ }^{[387)}$

Hall and Roshbash's team identified in early 1998 a new clock gene called cycle (cyc) from chromosome 3. They found that homozygous cyc mutant flies are completely arrhythmic. Mutant flies have little or no transcription of the per and tim genes. Cloning of the gene indicates that it 
also encodes a bHLH-PAS (basic helix-loop-helix and PAS domains) transcription factor and is a Drosophila homolog of the human protein BMAL1. Thus, CYC and CLK are both bHLH-PAS transcription factors. CYC/CLK heterodimer binds to per and tim $\mathrm{E}$ boxes and makes a major contribution to the circadian transcription of the clock genes. ${ }^{[39]}$

In 1999, Rosbash's team discovered a new clock gene and its protein. They named it circadianly regulated gene (crg-1). Like per and tim, $\mathrm{crg}$-1 oscillates with a $24 \mathrm{~h}$ period in light/dark conditions, with a maximal abundance at the beginning of the night. These oscillations persist in complete darkness and depend upon per and tim proteins. ${ }^{[40]}$ Around that time Young and Justin Blau found that a gene urille (uri) is also essential for proper circadian cycle, and that it is influenced by CLK and CYC to oscillate with the rhythm. In addition, they showed that CLK and VRI proteins independently regulate the levels of a neuropeptide, pigment dispersing factor (PDF) (later identified as the circadian pacemaker protein).$^{[41]}$ But the uri gene itself was discovered by French geneticists Hélène George and Régine Terracol, at the Institut Jacques Mono of Centre National de la Recherche Scientifique-Université Paris, two years before. George and Régine Terracol identified that uri encodes a new member of the basic leucine zipper (bZIP) family of transcription factors closely related to gene 9 of the frog Xenopus laevis, and is essential for embryonic development in Drosophila. ${ }^{[42]}$

In 2001, Young and his team demonstrated glycogen synthase kinase-3 (GSK-3) ortholog shaggy (SGG) as a regulator of TIM maturation and accumulation in the early night by causing phosphorylation. ${ }^{[43]}$ (GSK-3 was discovered in 1980 as an enzyme that phosphorylates glycogen synthase in rabbit muscle. $\left.{ }^{[4+1}\right)$ In 2003 , they further showed that PAR domain protein 1 (PDP1) and VRI acted concertedly for the repression and activation of CLK/CYC cycle. The noted that mutant (null) PDP1 lacked circadian rhythm, indicating that PDP1 is an essential clock gene. The interaction between CLK/CYC with VRI and PDP1 gives rise to another feedback loop, separate from but interlinked with PER/TIM cycle. ${ }^{445}$ (PDP1 was discovered in 1997 as a novel bZIP transcription factor requisite in cellular differentiation during Drosophila development. ${ }^{[46]}$ )

Now, these whole cohort of genes were discovered. But one mystery remains. Since light is the primary factor in circadian rhythm, then how does light influence these genes? In the late 1998, Hall and Roshbash's team discovered a mutant gene in the middle of the right arm of chromosome 3 at the position of a cryptochrome gene, a gene for sensitivity to blue light. They gave a rather catchy name, crybaby. They simultaneously identified the protein CRY as the main photoreceptor system. The activity of cry is under circadian regulation, and influenced by other genes such as per, tim, Clk, and cyc. ${ }^{[4]}$ The gene product CRY is a major light-sensitive (photoreceptor) protein in Drosophila. CRY belongs to a class of flavoproteins called cryptochromes-hence, the name CRY-that are sensitive to light. The Drosophila CRY protein is structurally and functionally very similar to that of the bacterial 6-4 photolyase. CRY was in fact originally discovered in 1993 by Margaret Ahmad and Anthony R. Cashmore, at the University of Pennsylvania, from the plant Arabidopsis thaliana. ${ }^{[48]}$ Different cryptochromes are involved in the circadian rhythms of plants and animals. Their resemblance to bacterial 6-4 photolyase indicates that they are replacement to photolyases during eukaryotic evolution..$^{[49]}$

In the mid-1998, Hall and Jae H. Park isolated a gene encoding a neuropeptide (protein acting on the nerve cells) in Drosophila. They named the protein pigment-dispersing factor (PDF), based on one of the roles it plays in crustacean body colour. ${ }^{[50]}$ The protein was initially discovered in 1993 by K. Ranga Rao and John P. Riehm, at the University of West Florida, as a member of pigment-dispersing hormones (PDHs). These PDHs control the colour changing pattern in the integument and eye of crustaceans. ${ }^{[51]}$ PDH in Drosophila was first discovered in 1995 by a German biologist Charlotte Helfrich-Förster at the Institut für Botanik, Tübingen, Germany. They found that PDH is produced by neurones and may play a role in circadian rhythm by interacting with PER-containing glial cells. ${ }^{[52]}$ Hall and Park found 
that $p d f$ gene is intronless and present in a single copy at 97B on chromosome 3 , but they did not find any effect or involvement in circadian rhythm. ${ }^{[50]}$ With the help of Rosbash's team, they found in 1999 that mutation in pdf causes circadian malfunction. They discovered that PDF is expressed by lateral neurone ventral clusters $\left(\mathrm{LN}_{\mathrm{v}}\right)$. When they selectively ablated the $\mathrm{LN}_{\mathrm{v}}$ neurones, circadian rhythm was disturbed, indicating that these neurones are the principal circadian pacemakers. This further showed that PDF is the principal neurotransmitter in circadian rhythm. ${ }^{[53]}$

In 2000, Roshbash's team discovered a new clock-regulated gene, which they named takeout (to). to is a member of a novel gene family and is implicated in circadian control of feeding behaviour. Its gene expression is down-regulated in all clock mutants. In wild-type flies, to mRNA exhibits daily cycling expression but with a novel phase, delayed relative to those of the bettercharacterised clock mRNAs, per and tim. ${ }^{[54]}$

\section{A Day in the Life... of Drosophila}

Drosophila spend their entire lives in small areas near the ground, and use their circadian clock to maintain their daily rhythms of rest and activity, so as to adjust their behaviour appropriately to the daily rhythms of their local environment. Compound eyes, ocelli, and HofbauerBuchner eyelets (HB eyelets) are the direct external light-detecting (photoreceptor) organs in Drosophila, of which the compound eyes are the largest and are the most important for light entrainment. It is important to note that the presence or function of external eyes is not prerequisite for Drosophila to respond to light input, and that circadian rhythms persist in constant darkness. ${ }^{[55]}$ Nonetheless, the photoreceptors are required for measuring the day length and detecting moonlight. In particular, the compound eyes are necessary for adjusting the phase of the activity rhythm, for differentiating long days from constant light, and for the normal masking effects of light, such as inducing activity by light and inhibition by darkness. ${ }^{[56]}$

There are two distinct activity peaks in Drosophila at approximately dawn and dusk in 12:12 hour light-dark cycles. These peaks are termed the $\mathrm{M}$ (for morning) and $\mathrm{E}$ (for evening) peaks respectively. They act as mutually coupled stim-
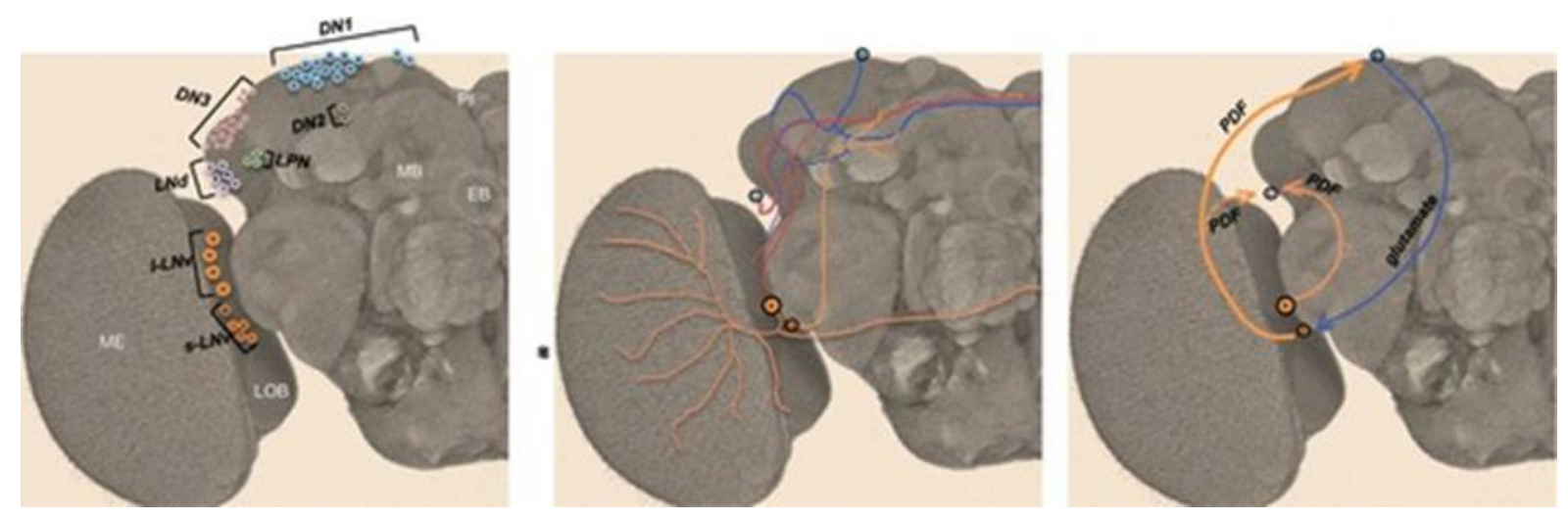

Fig. 4 | The clock neurons of the Drosophila brain. Left panel: seven groups of clock neurons. The lateral neurons are organized into a ventral cluster that include small $\left(s-L N_{v} s\right)$ and large $\left(I-L N_{v} s\right)$ cells, a dorsal cluster $\left(L N_{d} s\right)$ and a posterior cluster $\left(L P_{N} S\right)$. The dorsal neurons include three clusters designated as $D N_{1}, D N_{2}$ and $D N_{3}$. Several neuropiles are indicated: medulla $(\mathrm{ME})$ and lobula (LOB) in the optic lobe and pars intercerebralis ( $\mathrm{PI})$, mushroom bodies $(\mathrm{MB})$ and ellipsoid body (EB) in the central brain. Central panel: projections of the different clock neuron subsets: s$\mathrm{LN}_{\mathrm{v}} \mathrm{S}$ and I-LN $\mathrm{v}$ (orange), $\mathrm{LN}_{\mathrm{d}} \mathrm{S}$ and fifth PDF-negative S-LNv (red), $\mathrm{DN}_{1} \mathrm{~S}$ (blue). Right panel: communication between neuronal clusters involves PDF from $s-L N_{v} s$ to $L N_{d} s$ and $D N_{1} s$ as well as from I- $L N_{v} s$ to $L N_{d} s$, and glutamate from $D N_{1} s$ to s-LNvs. [Chatterjee A, Rouyer F (2016). Control of Sleep-Wake Cycles in Drosophila. In: (Sassone-Corsi P, Christen Y, editors) A Time for Metabolism and Hormones. Springer. CC BY-NC 2.5] 
uli in the brain and regulate the phase-angle between the two oscillators under different day lengths. This is the basis behind adaptation to changing activity pattern to different season of the year, such as short winter and long summer days. ${ }^{[57]}$ The light-sensitive proteins in the eye called, rhodopsins, are crucial in activating the $\mathrm{M}$ and $\mathrm{E}$ oscillations. Rhodopsin 1 and 6 are especially important because their mutation inhibits the masking effect of moonlight, which tends to lengthen the nocturnal activity. The masking effect is not influenced by the main circadian photoreceptor protein CRY ${ }^{[58]}$

In response to the environmental light cue, approximately 150 neurones (out of an estimated 100,000 neurones) in the fruit fly brain monitor the circadian rhythm. ${ }^{[59]}$ These neurones contain the core components of the molecular clock that act together to translate this intracellular cycling into rhythmic behaviour. The clock neurones are located in distinct clusters in the central brain (Fig. 4). The bestunderstood clock neurones are the large and small lateral ventral neurones (l-LN $\mathrm{N}_{V} \mathrm{~S}$ and $\mathrm{s}$ $\mathrm{LN}_{\mathrm{v}} \mathrm{s}$ ) of the optic lobe. These neurones apparently play a major role as pacemakers for locomotor activity rhythms. They produce PDF, a molecule neuropeptide that acts as a circadian neuromodulator between different clock neurones. Without PDF or in pdf mutant, there is phase-advanced $\mathrm{E}$ activity peak under LD conditions, as well as inhibiting the shifting of $\mathrm{M}$ and E peaks under long-day conditions. ${ }^{[60]}$

Drosophila circadian machinery keeps time via daily fluctuations of clock-related proteins which interact in what is called a transcriptiontranslation feedback loop (Fig. 5). The core clock mechanism consists of two interdependent feedback loops, namely the period/timeless (PER/TIM) loop and the Clock/cycle (CLK/CYC) loop. ${ }^{[61]}$ The CLK/CYC loop occurs during the day in which both CLK and CYC proteins are produced. CLK/CYC heterodimer acts as transcription factor and binds to a promoter element called $\mathrm{E}$ box to initiate the transcription of the per and tim genes, around mid-day. DNA is transcribed and translated to produce PER and TIM proteins in the cytoplasm, and this production exhibits a smooth increase in levels over the course of the day. Their RNA levels peak early in the evening and protein levels peak around daybreak. ${ }^{[59]}$ But their proteins levels are maintained at constantly low level until dusk, because daylight also activates the dbt gene. DBT protein induces post-translational modifications by causing phosphorylation and turnover of monomeric PER proteins. As PER is translated in the cytoplasm, it is actively phosphorylated by DBT (as an enzyme casein kinase $1 \varepsilon$ ) and casein kinase 2 (synthesised by And and Tik) as a prelude to premature degradation. The actual degradation is through the ubiquitin-proteasome pathway, and is carried out by a ubiquitin ligase called Slimb (supernumery limbs). (Slimb was discovered in 1998 as an F-box/WD40-repeat protein involved in body growth and patterning during development; ${ }^{[62]}$ and its role in circadian rhythm was discovered in the late 2002..$^{\left[63\left[{ }^{64}\right]\right.}$ At the same time, TIM itself is phosphorylated by shaggy, whose activity weans off after sunset. DBT gradually disappears, and withdrawal of DBT promotes PER molecules to get stabilised by physical association with TIM. Hence, maximum production of PER and TIM occurs at dusk. At the same time, CLK/CYC also directly activates vri and Pdp1 (the gene for PAR domain protein 1). VRI accumulates first, 3-6 hour earlier, and starts to repress Clk; but the incoming of PDP1 creates a competition by activating Clk. PER/TIM dimer accumulates in the early night and translocate in an orchestrated fashion into the nucleus several hours later, and binds to CLK/CYC dimers. Bound PER completely stop the transcriptional activity of Clk and cyc. ${ }^{[65]}$

In the wee hour of the morning, the onset of light degrades PER and TIM proteins in a network of transcriptional activation and repression. First, light activates the cry gene, and producing CRY as an autonomous photoreceptor. CRY is produced by most clock neurones in the brain, including morning (M) and evening (E) neurones; but not all clock neurones are equally sensitive to light. Although CRY is deep inside the brain, it is sensitive to UV and blue light, and thus easily signals the brain cells the onset of light. A bright light pulse lasting for several min- 


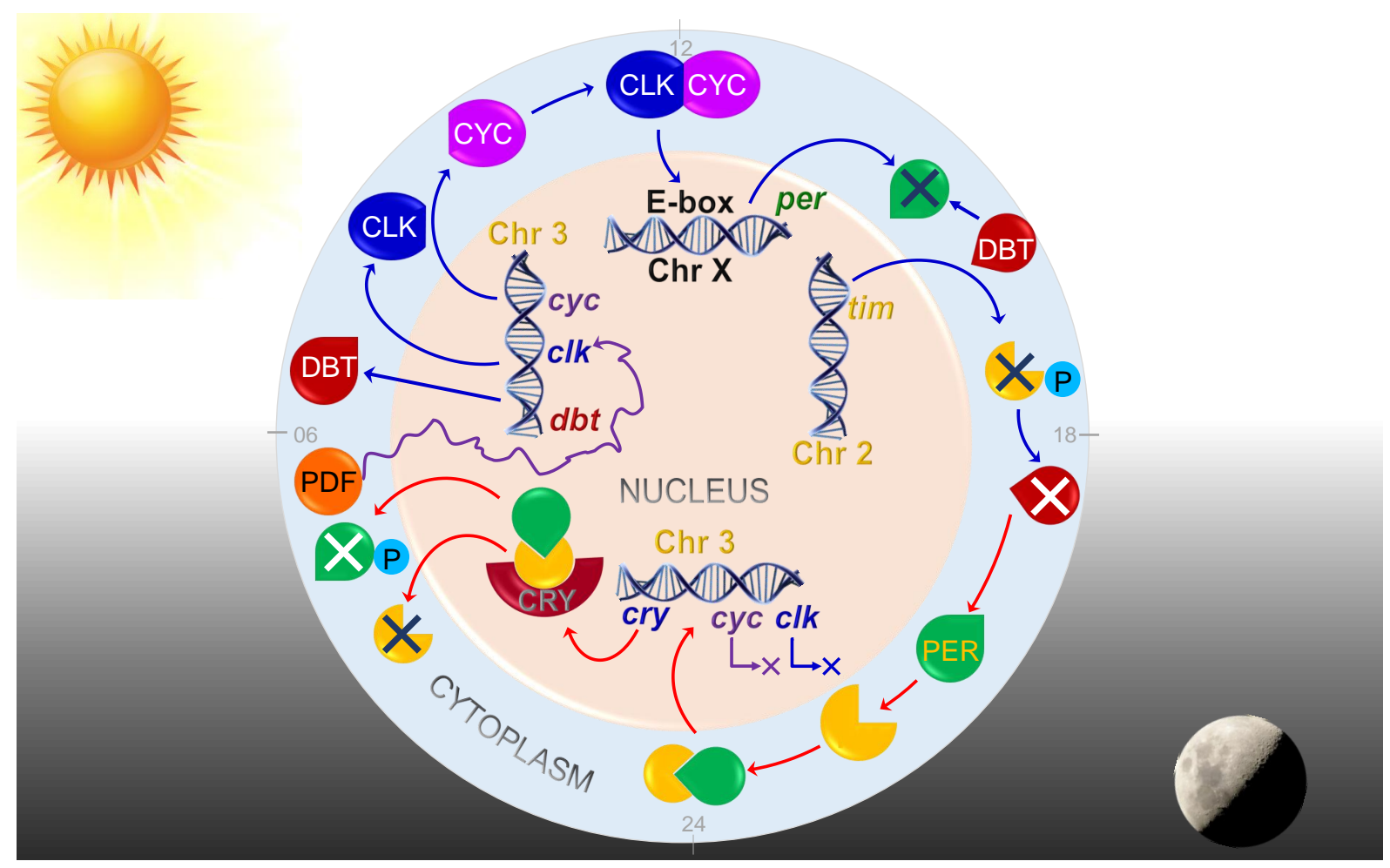

Fig. 5 | A very simplified overview Drosophila circadian system.

utes is enough to activate cry. Once CRY is produced, it irreversibly and directly binds to TIM causing it to break down through proteosomedependent ubiquitin-mediated degradation. The CRY's photolyase homology domain is sufficient for light detection and phototransduction, whereas the carboxyl-terminal domain regulates CRY stability, CRY-TIM interaction, and circadian photosensitivity. These functions differ from those in plants indicating that CRY in insect and plant act through different mechanisms. ${ }^{[6]}$ Another protein JET helps in the ubiquitination and subsequent degradation. (JET was discovered in 2006 as a result of mutation called jetlag that induced a sort of jetlag in Drosophila. [67]) Thus, PER/TIM dimer dissociates, and the unbound PER becomes unstable. PER undergoes progressive phosphorylation and ultimately degradation. Absence of PER and TIM allows activation of Clk and cyc genes. Thus, the clock is reset to commence the next bout of circadian cycle for "a day in the life" of D. melanogaster.

\section{References}

I. Nobel Foundation (2017). The Nobel Prize in Physiology or Medicine 2017. www.nobelprize.org. Nobel Media $\mathrm{AB}$.

2. Reddy, P.; Zehring, W.A.; Wheeler, D.A.; Pirrotta, V.; Hadfield, C.; Hall, J.C.; Rosbash, M. (1984). Molecular analysis of the period locus in Drosophila melanogaster and identification of a transcript involved in biological rhythms. Cell. 38 (3): 70I-7IO.

3. Zehring, W.A.; Wheeler, D.A.; Reddy, P.; Konopka, R.J.; Kyriacou, C.P.; Rosbash, M.; Hall, J.C. (1984). Pelement transformation with period locus DNA restores rhythmicity to mutant, arrhythmic Drosophila melanogaster. Cell. 39 (2 Pt I):369-376.

4. Bargiello, T.A.; Jackson, F.R.; Young, M.W. (1984). Restoration of circadian behavioural rhythms by gene transfer in Drosophila. Nature. 312 (5996): 752-754. 
5. Bargiello, T.A.; Young, M.W. (1984). Molecular genetics of a biological clock in Drosophila. Proceedings of the National Academy of Sciences of the United States of America. 8I (7): 2I42-2I46.

6. Roberts, R.J. (20I5). Ten simple rules to win a Nobel Prize. PLoS Computational Biology. II (4): eIo04084.

7. Kalmus, H. (1935). Periodizität und Autochronie (= Ideochronie) als zeitregelnde Eigenschaften des Organismus [Periodicity and autochrony (= ideochrony) as time -regulating properties of the organism]. Biologia Generalis. II: 93-II4.

8. Bünning, E. (1935). Zur Kenntnis der endonomen Tagesrhythmik bei Insekten und bei Pflanzen [To the knowledge of the endogenous day rhythms in insects and plants]. Berichte der Deutschen Botanischen Gesellschaft. 53: 594-623.

9. Kalmus, H. (1938). Die Lage des Aufnahmeorganes für die Schlupfperiodik von Drosophila [The location of the receiving organ for the hatching period of Drosophila]. Zeitschrift für vergleichende Physiologie. 26 (3): 362-365.

Io. Kalmus, H. (1940). Diurnal rhythms in the Axolotl larva and in Drosopbila. Nature. 145 (3663): $72-73$.

II. Welsh, J.H. (1938). Diurnal rhythms. The Quarterly Review of Biology. 13 (2): 123-139.

I2. Pittendrigh, C.S. (1954). On temperature independence in the clock system controlling emergence time in Drosophila. Proceedings of the National Academy of Sciences of the United States of America. 40 (10): 1018-1029.

13. Benzer, S. (1967). Behavioral mutants of Drosophila isolated by countercurrent distribution. Proceedings of the National Academy of Sciences of the United States of America. 58 (3): III2-III9.

I4. Konopka, R.J.; Benzer, S. (197I). Clock mutants of Drosophila melanogaster. Proceedings of the National Academy of Sciences of the United States of America. 68 (9): 2II2-2II6.

15. Konopka, R.J. (1979). Genetic dissection of the Drosophila circadian system. Federation Proceedings. 38 (I2): 2602-2605.

I6. Konopka, R.J.; Wells, S. (1980). Drosophila clock mutations affect the morphology of a brain neurosecretory cell group. Journal of Neurobiology. II (4): 4II-4I5.

17. Smith, R.F.; Konopka, R.J. (198I). Circadian clock phe- notypes of chromosome aberrations with a breakpoint at the per locus. Molecular \& General Genetics. 183 (2): 243-245I.

18. Kyriacou, C.P.; Hall, J.C. (1980). Circadian rhythm mutations in Drosophila melanogaster affect short-term fluctuations in the male's courtship song. Proceedings of the National Academy of Sciences of the United States of America. 77 (II): 6729-6733.

19. Jackson, F.R.; Bargiello, T.A.; Yun, S.H.; Young, M.W. (1986). Product of per locus of Drosophila shares homology with proteoglycans. Nature. 320 (6058): 185-I88.

2o. Hamblen, M.; Zehring, W.A.; Kyriacou, C.P.; Reddy, P.; Yu, Q.; Wheeler, D.A.; Zwiebel, L.J.; Konopka, R.J.; Rosbash, M.; Hall, J.C. (1986). Germ-line transformation involving DNA from the period locus in Drosophila melanogaster: overlapping genomic fragments that restore circadian and ultradian rhythmicity to $\operatorname{per}^{\circ}$ and per mutants. Journal of Neurogenetics. 3 (5): 249-29I.

2I. Reddy, P.; Jacquier, A.C.; Abovich, N.; Petersen, G.; Rosbash, M. (1986). The period clock locus of $D$. melanogaster codes for a proteoglycan. Cell. 46 (I): 536I.

22. Rosato, E.; Tauber, E.; Kyriacou, C.P. (2006). Molecular genetics of the fruit-fly circadian clock. European Journal of Human Genetics. 14 (6): 729-738.

23. Yu, Q.; Jacquier, A.C.; Citri, Y.; Hamblen, M.; Hall, J.C.; Rosbash, M. (1987). Molecular mapping of point mutations in the period gene that stop or speed up biological clocks in Drosophila melanogaster. Proceedings of the National Academy of Sciences of the United States of America. 84 (3): 784-788.

24. Baylies, M.K.; Bargiello, T.A.; Jackson, F.R.; Young, M.W. (1987). Changes in abundance or structure of the per gene product can alter periodicity of the Drosophila clock. Nature. 326 (6III): 390-392.

25. Siwicki, K.K.; Eastman, C.; Petersen, G.; Rosbash, M.; Hall, J.C. (1988). Antibodies to the period gene product of Drosophila reveal diverse tissue distribution and rhythmic changes in the visual system. Neuron. I (2): I4I - I5O.

26. Hardin, P.E.; Hall, J.C.; Rosbash, M. (1990). Feedback of the Drosophila period gene product on circadian cycling of its messenger RNA levels. Nature. 343 (6258): $536-540$.

27. Sehgal, A.; Price, J.L.; Man, B.; Young, M.W. (1994). 
Loss of circadian behavioral rhythms and per RNA oscillations in the Drosophila mutant timeless. Science. 263 (5153): 1603-1606.

28. Gekakis, N.; Saez, L.; Delahaye-Brown, A.M.; Myers, M.P.; Sehgal, A.; Young, M.W.; Weitz, C.J. (1995). Isolation of timeless by PER protein interaction: defective interaction between timeless protein and long-period mutant PER ${ }^{\mathrm{L}}$. Science. 270 (5237): 8II-8I5.

29. Sehgal, A.; Rothenfluh-Hilfiker, A.; Hunter-Ensor, M.; Chen, Y.; Myers, M.P.; Young, M.W. (1995). Rhythmic expression of timeless: a basis for promoting circadian cycles in period gene autoregulation. Science. 270 (5237): 8о8-8io.

3o. Myers, M.P.; Wager-Smith, K.; Wesley, C.S.; Young, M.W.; Sehgal, A. (1995). Positional cloning and sequence analysis of the Drosophila clock gene, timeless. Science. 270 (5237): 805-808.

31. Myers, M.P.; Wager-Smith, K.; Rothenfluh-Hilfiker, A.; Young, M.W. (1996). Light-induced degradation of TIMELESS and entrainment of the Drosopbilacircadian clock. Science. 271 (5256): 1736-1740.

32. Price, J.L.; Blau, J.; Rothenfluh, A.; Abodeely, M.; Kloss, B.; Young, M.W. (1998). double-time is a novel Drosopbila clock gene that regulates PERIOD protein accumulation. Cell. 94 (I): 83-95.

33. Hamblen-Coyle, M.; Konopka, R.J.; Zwiebel, L.J.; Colot, H.V.; Dowse, H.B.; Rosbash, M.; Hall, J.C. (1989). A new mutation at the period locus of Drosophila melanogaster with some novel effects on circadian rhythms. Journal of Neurogenetics. 5 (4): 229-256.

34. Dushay, M.S.; Konopka, R.J.; Orr, D.; Greenacre, M.L.; Kyriacou, C.P.; Rosbash, M.; Hall, J.C. (1990). Phenotypic and genetic analysis of Clock, a new circadian rhythm mutant in Drosophila melanogaster. Genetics. I25 (3): $557-578$.

35. Konopka, R.J.; Smith, R.F.; Orr, D. (199I). Characterization of Andante, a new Drosophila clock mutant, and its interactions with other clock mutants. Journal of Neurogenetics. 7 (2-3): I03-II4.

36. Konopka, R.J.; Hamblen-Coyle, M.J.; Jamison, C.F.; Hall, J.C. (1994). An ultrashort clock mutation at the period locus of Drosophila melanogaster that reveals some new features of the fly's circadian system. Journal of Biological Rhythms. 9 (3-4): 189-216.

37. Lin, J.M.; Kilman, V.L.; Keegan, K.; Paddock, B.; Emery
-Le, M.; Rosbash, M.; Allada, R. (2002). A role for casein kinase 2alpha in the Drosophila circadian clock. Nature. 420 (6917): 816-820.

38. Glover, C.V.; Shelton, E.R.; Brutlag, D.L. (1983). Purification and characterization of a type II casein kinase from Drosophila melanogaster. The Journal of Biological Chemistry. 258 (5): 3258-3265.

39. Rutila, J.E.; Suri, V.; Le, M.; So, W.V.; Rosbash, M.; Hall, J.C. (1998). CYCLE is a second bHLH-PAS clock protein essential for circadian rhythmicity and transcription of Drosophila period and timeless. Cell. 93 (5): 805814 .

40. Suri, V.; Lanjuin, A.; Rosbash, M. (1999). TIMELESSdependent positive and negative autoregulation in the Drosophila circadian clock. The EMBO Journal. I8 (3): 675-86.

4I. Blau, J.; Young, M.W. (1999). Cycling vrille expression is required for a functional Drosophila clock. Cell. 99 (6): 66I-67I.

42. George, H.; Terracol, R. (1997). The vrille gene of Drosophila is a maternal enhancer of decapentaplegic and encodes a new member of the bZIP family of transcription factors. Genetics. 146 (4): 1345-1363.

43. Martinek, S.; Inonog, S.; Manoukian, A.S.; Young, M.W. (20oI). A role for the segment polarity gene shaggy/GSK-3 in the Drosophila circadian clock. Cell. ros (6): 769-779.

44. Embi, N.; Rylatt, D.B.; Cohen, P (1980). Glycogen synthase kinase-3 from rabbit skeletal muscle. Separation from cyclic-AMP-dependent protein kinase and phosphorylase kinase. European Journal of Biochemistry. 107 (2): 519-527.

45. Cyran, S.A.; Buchsbaum, A.M.; Reddy, K.L.; Lin, M.C.; Glossop, N.R.; Hardin, P.E.; Young, M.W.; Storti, R.V.; Blau, J (2003). vrille, PdpI, and dClock form a second feedback loop in the Drosopbila circadian clock. Cell. $\mathrm{II2}$ (3): 329-34I.

46. Lin, S.C.; Lin, M.H.; Horváth, P.; Reddy, K.L.; Storti, R.V. (1997). PDPI, a novel Drosophila PAR domain bZIP transcription factor expressed in developing mesoderm, endoderm and ectoderm, is a transcriptional regulator of somatic muscle genes. Development. $\mathbf{2 4}$ (22): $4685-4696$.

47. Emery, P.; So, W.V.; Kaneko, M.; Hall, J.C.; Rosbash, M. (1998). CRY, a Drosophila clock and light-regulated 
cryptochrome, is a major contributor to circadian rhythm resetting and photosensitivity. Cell. 95 (5): 669679.

48. Ahmad, M.; Cashmore, A.R. (1993). $H Y_{4}$ gene of $A$. thaliana encodes a protein with characteristics of a bluelight photoreceptor. Nature. 366 (6451): 162-166.

49. Mei, Q.; Dvornyk, V. (2015). Evolutionary history of the photolyase/cryptochrome superfamily in eukaryotes. PloS One. ro (9): eor 35940.

5o. Park, J.H.; Hall, J.C. (1998). Isolation and chronobiological analysis of a neuropeptide pigment-dispersing factor gene in Drosophila melanogaster. Journal of Biological Rhythms. 13 (3): 219-228.

51. Rao, K.R.; Riehm, J.P. (1993). Pigment-dispersing hormones. Annals of the New York Academy of Sciences. 680: $78-88$.

52. Helfrich-Förster, C. (1995). The period clock gene is expressed in central nervous system neurons which also produce a neuropeptide that reveals the projections of circadian pacemaker cells within the brain of Drosophila melanogaster. Proceedings of the National Academy of Sciences of the United States of America. 92 (2): 612-616.

53. Renn, S.C.; Park, J.H.; Rosbash, M.; Hall, J.C.; Taghert, P.H. (1999). A $p d f$ neuropeptide gene mutation and ablation of PDF neurons each cause severe abnormalities of behavioral circadian rhythms in Drosophila. Cell. 99 (7): 79I-802.

54. So, W.V.; Sarov-Blat, L.; Kotarski, C.K.; McDonald, M.J.; Allada, R.; Rosbash, M. (200o). takeout, a novel Drosophila gene under circadian clock transcriptional regulation. Molecular and Cellular Biology. 20 (I8): 6935 -6944 .

55. Veleri, S.; Wülbeck, C. (2004). Unique self-sustaining circadian oscillators within the brain of Drosopbila melanogaster. Chronobiology International. 21 (3): 329342.

56. Rieger, D.; Stanewsky, R.; Helfrich-Förster, C. (2003). Cryptochrome, compound eyes, Hofbauer-Buchner eyelets, and ocelli play different roles in the entrainment and masking pathway of the locomotor activity rhythm in the fruit fly Drosophila melanogaster. Journal of Biological Rhythms. I8 (5): 377-391.
57. Yoshii, T.; Rieger, D.; Helfrich-Förster, C. (2OI2). Two clocks in the brain: an update of the morning and evening oscillator model in Drosophila. Progress in Brain Research. 199 (I): 59-82.

58. Schlichting, M.; Grebler, R.; Peschel, N.; Yoshii, T.; Helfrich-Förster, C. (2014). Moonlight detection by Drosophila's endogenous clock depends on multiple photopigments in the compound eyes. Journal of Biological Rhythms. 29 (2): 75-86.

59. Nitabach, M.N.; Taghert, P.H. (2008). Organization of the Drosophila circadian control circuit. Current Biology. 18 (2): 84-93.

6o. Yoshii, T.; Hermann-Luibl, C.; Helfrich-Förster, C. (2015). Circadian light-input pathways in Drosophila. Communicative ES Integrative Biology. 9 (I): eIIO2805.

6I. Boothroyd, C.E.; Young, M.W. (2008). The in(put)s and out(put)s of the Drosophila circadian clock. Annals of the New York Academy of Sciences. II29: 350-357.

62. Jiang, J.; Struhl, G. (1998). Regulation of the Hedgehog and Wingless signalling pathways by the F-box/WD40repeat protein Slimb. Nature. 39I (6666): 493-496.

63. Grima, B.; Lamouroux, A.; Chélot, E.; Papin, C.; Limbourg-Bouchon, B.; Rouyer, F. (2002). The F-box protein slimb controls the levels of clock proteins period and timeless. Nature. 420 (6912): 178-182.

64. Ko, H.W.; Jiang, J.; Edery, I. (2002). Role for Slimb in the degradation of Drosophila Period protein phosphorylated by Doubletime. Nature. 420 (6916): 673678.

65. Helfrich-Förster, C. (2005). Neurobiology of the fruit fly's circadian clock. Genes, Brain, and Bebavior. 4 (2): $65-76$.

66. Busza, A.; Emery-Le, M.; Rosbash, M.; Emery, P. (2004). Roles of the two Drosophila CRYPTOCHROME structural domains in circadian photoreception. Science. 304 (5676): 1503-1506.

67. Koh, K.; Zheng, X.; Sehgal, A. (2006). JETLAG resets the Drosophila circadian clock by promoting lightinduced degradation of TIMELESS. Science. 312 (578I): I809-I8I2. 